\title{
Research on the Current Situations, Problems and Countermeasures of Smart Library Constructions in China
}

\author{
Wang Hongmei
}

(Shandong normal university library, Jinan city, Shandong province, 250014)

Keywords: Smart library, Smart librarian, Smart service

\begin{abstract}
Smart library is a higher development form of library after the digital library and the compound library, which relies on sensors, cloud computing and other technologies to achieve interoperability among books and readers to provide a full range of smart services. At present, the construction of smart library in our country is still at the stage of exploration. There are still some problems in the development of smart library, such as the problems of technical support, librarian cultivation and user experience. In view of these problems, this paper puts forward the corresponding solutions to provide some references for the relevant researchers.
\end{abstract}

\section{Current Situations of Smart Library Constructions in China}

The smart library is a kind of intelligent construction applying the intelligent technology to the library construction. It is the organic combination and innovation of intelligent building, highly automated management and digital library. One stop search, mobile library and data mining technology have become one of the core technologies of Library Construction in our country. Since Singapore in the construction of the library information resources management system into the successful development of library technology and, our country will be the development of technology into the management of the information resources in the museum, successfully opened books borrowed, accurate search and independent automatic sorting, automatic counting books and other service functions. In data management and mining, through the management of information database, operators and domestic libraries to establish a good cooperation mechanism, the joint research and development of knowledge collection system, effectively enhance the knowledge conversion rate of information resources. Smart library environment, because of the use of a variety of network channels, communication tools, information is ubiquitous, three-dimensional interconnection, can be interconnected with the library information management system, such as seat. It can be interconnected with others; interconnection of books. The smart library can take the initiative to perceive the user's needs and provide personalized intelligent services. At the same time, intelligent buildings, from temperature, brightness, humidity, through strict and accurate regulation, to create a comfortable environment for readers. As the living conditions improve, protect the consciousness of self-interests gradually increased, but from the social attribute of the dimension analysis, the construction of information library is for people's knowledge, enhance the ability to provide convenient and ultimately achieve the purpose to enhance the comprehensive national strength. Based on this development goal, it is essential to analyze reader's reading habit and information demand in depth. Therefore, the user information analysis software system developed by the joint library software development company of China has created favorable conditions for its development.

\section{Problems of Smart Library Constructions in China}

Problem of Technical Support. The construction of smart library needs the comprehensive application and cooperative service of modern information technology. We need to combine digital technology, Internet of things technology, network information technology, cloud computing, information technology and intelligent information technology organically. For libraries that are not technically advanced, there is still a long way to go before dealing with the complexity of the 
technology. At present, the research and application of the Internet of things is still in the primary stage, and the construction of the wisdom of the library has just departed, the research and application of key technologies still need further development and improvement and breakthrough. In the smart library, the perception of the entity literature information, the perception of the user's identity information, the perception of the library's various equipment and all kinds of environmental information depend on the information perception node. At this stage, the ability is not much, sensor types of information perception and processing of information is limited, and sensor nodes in volume, power consumption, life, stability and cost also has the advantage of being one of the key technologies of the smart library. RFID technology has just entered the industrialization application stage, which still faces many challenges, such as hidden label function, label low anti-jamming and middleware. The application is not perfect industrial chain management solutions. At present, the technology used in the primary stage of Smart library in our country is mainly low frequency. At the present stage of smart library there are many technical problems to be overcome, such as useful resources in the mass and disorder in the data set, investigation organization, sorting, processing, filtering, storage, communication and feedback, support from technology and network interface transmission technology. These problems are urgent to solve.

Problem of Librarian Cultivation. Librarian is the living soul of Library and the representative of humanistic spirit of library. Smart Library is committed to providing personalized knowledge services to users, with the wisdom of the physical equipment, wireless networks, data resources and other support at the same time, the wisdom of librarians is also essential. The librarian of the library is no longer simply gatekeeper, high-quality talent but has a professional knowledge of library information, through the deep mining of user needs, real-time tracking of user behavior, timely push the required information. And can analyze and integrate the resources of the museum and provide characteristic discipline services. The wisdom of library services cannot be separated from the librarians. But at present, the construction of China's Library of intelligent buildings construction, the construction of digital resources construction, information space, advanced equipment such as the construction of key complement. The wisdom of librarian team construction is lagging, there is no domestic for librarian professional qualification training, no qualification standard, the result is that, despite the soft hardware resources are abundant, but the quality of the library service has increased, compared to the past, but has not yet reached the level of wisdom. The ability and quality of librarians cannot be synchronized with the construction and development of libraries, which is one of the important reasons for the slow development of library construction in China. In the construction of the smart library, the existing parts of the library and personnel organizations are bound to be changed. Some of the personnel organizations have gradually disappeared, while some of them need to be greatly strengthened. For example, in the smart library environment, the circulation work will gradually fade out, and the active and personalized wisdom service and reference service will be further strengthened. To provide better information service to readers, more librarians are required to participate in it, and their service ability is of great importance to the realization of the library's functions and functions.

Problem of User Experience. Most users come to the library, after all, not with related knowledge of people, in the library, the wisdom of all kinds of services, may be this or that problem, resulting in no good experience to use user services in the wisdom of the library, not up to the real intelligence services cannot meet the needs of their own. Smart library in the application of RFID technology is relatively simple, currently mainly used in the book circulation in this respect, but in fact, the user's real information needs, on the one hand, should be the libraries most eagerly concerned about. This put forward higher request to the library service. The current development of the smart library was still in the primary stage, to have a long way to go to achieve this goal, therefore, should pay more attention to the real needs of mining user information and provide diversification, for a full range of services in the future smart library. The personal privacy of the user is the most important. At present, the library is mainly used as a sensor tag to obtain information, because it has the characteristics of identity, will cause the electronic tag is very easy by uncontrolled scanning, positioning and tracking, the internal storage of personal information has the possibility of leakage, 
the user privacy security faces many potential risks. The transmission to the reader has certain security risks, and has some threats to the privacy of users and the information security of the library. In this all-round, three-dimensional, interactive and interconnected environment, once the network has been attacked by viruses or hackers, the fortunes of the library will be destroyed, and personal privacy will be violated.

\section{Countermeasures of Smart Library Constructions in China}

Develop Technical Technologies. The application of new technology of library automation management system, realize the transition to self-service, the liberation of the librarian's physical labor, breaking the constraints of time service, the special service of the library to be carried out, such as discipline service, space services, multimedia services. It follows is the appearance and application of a new round of technology, which promotes the development of librarians' mental work. Then, the ubiquitous services based on the Internet of things and other technologies have been realized. As a social knowledge service organization rather than a technology research institution, libraries do not have sufficient resources for new technology research and development, that is, the creators of non-information technology, but must be the technology users. Library in the application of technology, most of the implementation, which is understandable, but should fully combine the library discipline characteristics, technological innovation, application research, improve the applicability of technology. As the emergence of sensor technology and RFID technology, the library community has started the research of intelligent robot library, and has made some progress, but it is still in the process of research and development. Review and re orientation of library value mission. At the same time, it also should be its own technology and library integrated management system, data management software platform, application integration and docking networking problems into account, to solve the design basis of different systems, different standard protocol for information exchange and information exchange problem. The library to identify its own vision, mission and values, strengthen communication and cooperation with the government and all sectors of society, to get more financial support, get more right to speak and the degree of social concern, change from passive to active, actively seize the opportunity to reshape the service mode and re design. Accelerate the reunification of the Internet of things technology standards, to avoid duplication of standards caused by repeated development and other waste of resources.

Strengthen Librarian Cultivation. Introduce the competition mechanism of librarians to arouse the enthusiasm of librarians and maintain the steady and rapid development of Library cause. Smart library environment, the transformation of information services to knowledge services, the need for intelligent librarians, such as personalized service, reference services. On the other hand, the development of technology requires higher levels of librarians to master. Therefore, librarians must constantly improve their knowledge level, update their knowledge structure, keep pace with the times and improve their skills, so as not to be left behind in front of the technology, so as not to be eliminated by the times. The existing librarians select more attention to professional orientation and educational level, and the entry threshold of the library is relatively high, and the recruitment efficiency is low. Revitalize the stock of human resources. The existing librarians should be classified and used according to whether they have the wisdom of library knowledge and assign different posts and departments. Librarians with intelligence literacy should be centrally assigned to the intelligent service systems sector and should be encouraged to continue to enhance their capacity and innovation. Librarians who do not possess the wisdom and ability to train their intelligence, service consciousness and ability. Society and knowledge are constantly changing and developing, through various training and learning salon, exchange of experience, cultivate the wisdom of librarian's humble attitude, and with the help of various learning tools for lifelong learning habits, through mutual exchanges, to achieve common progress. Introduce the competition mechanism of librarians to arouse the enthusiasm of librarians and maintain the steady and rapid development of library cause. Librarians should establish the concept of service-oriented. With keen observation, the user can tap the information to the real needs of users, personalized service and the professional point of view to provide users with a high effective and convenient. We should speed up the construction of 
professional qualification certification system for libraries and purify and strengthen the professional ranks of libraries from the source.

Improve User Experience. Library as a service organization, service is the eternal theme of the library. Intelligence service is always the research hotspot of smart library. The future research focus on the wisdom of the service will focus on how to use big data, cloud computing, wearable devices, remote sensing, positioning and a series of technical services, high perception of users, to provide more in line with the needs of readers and the higher level, more personality, more wisdom or service system of library service for readers and so on. Review and re orientation of library value mission. The library to identify its own vision, mission and values, strengthen communication and cooperation with the government and all sectors of society, to get more financial support, get more right to speak and the degree of social concern, change from passive to active, actively seize the opportunity to reshape the service mode and re design. Through the mobile phone and multimedia information carrier, readers enter the ubiquitous learning and leisure environment, to ensure that most documents and materials can be used to the maximum. Both the intelligent library and the digital library have the characteristics of digitalization and networking, but there are obvious differences between the two. These characteristics of the intelligent library have been organically integrated with its internal characteristics and essential pursuit of efficiency and convenience. Intelligent library is a product of intelligence, networking, globalization and social informatization based on digitalization of libraries. It is the continuity and sublimation of the concept and practice of the development of digital libraries. The wisdom of the library is not just a physical combination of digital Library of library resources, but the integration of further chemical library with the support of information technology and comprehensive service and excellent quality management, is the global library development solutions. The application of Internet of things RFID technology in the library has realized the wisdom of the whole business process from the storage to the shelves, and saved the labor force to the greatest extent. Strengthen the Internet thinking of library and emphasize the core value of library. Inside the library ubiquitous network environment as well as the development of the global Internet, to build the library between the sharing of resources and human resources will become the trend of total public employment, libraries should strengthen the Internet thinking, deepen cooperation; on the other hand, adhere to the core value of library, intelligent construction period, to put an end to absolute technical theory, reuse technology at the same time, pay attention to cultural construction; while preserving the cultural heritage of mankind, promote free access to knowledge. At present, some libraries have developed some fees and services, and there is a combination of libraries and bookstores.

\section{Conclusion}

Libraries are shouldering more and more important responsibilities in national construction and social development. Advanced support technology, high-quality librarians and good user experience have become the important development goals of our smart library. Although the construction of smart library has not achieved the advanced intelligent function, with the development of cloud computing and networking technology, the future smart library in China will be more and more intelligent.

\section{References}

[1] Wang Jialing. Construction of the Smart Library Based on Perspective of Smart Elements [J]. Library Work and Study, 2017(7): 41-44+49.

[2] Zhou Ruihua, Sun Haiying, Zong Mingguo. On Necessity and Problems of Constructing Smart Library in University [J]. Information Research, 2014(10): 109-111.

[3] Ling Yufei, Zhou Liuli. Discussion on Existing Problems in Traditional RFID Application Mode and the Construction of New Smart Library [J]. Sci-Tech Information Development \& Economy, 2014, 24(16): 61-62. 
[4] Zhu Sengsheng. Several Studies on Smart Library Issues in the Age of Big Data [J]. Library \& Information, 2013(5): 126-128.

[5] Gong Zhao. Construction of Smart library and Study on Wisdom Service [J]. Value Engineering, 2017(18): 235-236. 